\title{
Effects of Skin-to-Skin Care During Cesareans: A Quasiexperimental Feasibility/Pilot Study
}

\author{
Jeannette T. Crenshaw, Ellise D. Adams, ${ }^{2}$ Richard E. Gilder, \\ Kristine DeButy, ${ }^{3}$ and Kristin L. Scheffer ${ }^{4}$
}

\begin{abstract}
Introduction: Our aim was to describe feasibility and outcomes of skin-to-skin care (SSC) that began during cesarean surgery and continued, uninterrupted, for about 5 hours. We described maternal/newborn measures of physiologic stability and stress; maternal measures of comfort; maternal satisfaction with surgery and SSC; and exclusive breast milk feeding at discharge.

Materials and Methods: We used a quasiexperimental, time-interrupted design and randomly assigned women to receive SSC that began during surgery (Group 1, intervention; $n=20$ ) or after surgery, before transfer to recovery (Group 2, standard care; $n=20$ ). We analyzed differences across time and for five observations: before transfer to the operating room (OR); in the OR, about 20 minutes after birth; in the recovery room, about 1 hour after admission; in the New Family Center (NFC), about 1 hour after admission; and in the NFC, about 2 hours after admission.

Results: Group 1 began SSC an average of 0.89 minutes after birth and continued an average of 300 minutes and Group 2 began an average of 46 minutes after birth and continued an average of 126 minutes. Women who began SSC during surgery were more satisfied with the experience $(p=0.015)$ and had lower levels of salivary cortisol across time $(p=0.003)$. We found no negative effects on maternal or newborn measures of physiologic stability and no difference in exclusive breast milk feeding rates at discharge.

Conclusion: Immediate and uninterrupted SSC during medically uncomplicated cesarean surgery is a feasible, low-cost intervention that can safely begin during surgery and continue, uninterrupted, for extended durations.
\end{abstract}

Keywords: skin-to-skin contact, skin-to-skin care, cesarean birth, maternal satisfaction with cesarean, newborn thermoregulation

\section{Introduction}

A T THE MOMENT of birth, most mothers and newborns having uncomplicated cesareans are alert, responsive, medically stable, and ready to begin skin-to-skin care (SSC), a significant determinant of optimal maternal and newborn outcomes. ${ }^{1-4}$ No evidence supports the notion that the benefits of SSC apply only to vaginal birth or that SSC should be delayed or interrupted in women having an uncomplicated cesarean. ${ }^{5-7}$ Experts worldwide recommend immediate and uninterrupted SSC for all women, regardless of feeding preference, for an hour or more. ${ }^{2-4}$ In addition, experts recommend that routine procedures such as assessments are done during SSC and that nonemergent procedures be postponed until after this critical, time-limited, and psychophysiologically sensitive period..$^{2,3,8}$

However, SSC in women having uncomplicated cesareans often is delayed, shorter in duration than recommended, or absent. $^{1,9-11}$ The global rise in the rate of surgical births ${ }^{12,13}$ means at least one out of every three mothers and newborns worldwide are exposed to the potential and known risks of separation and deprived of the optimal outcomes associated with immediate and uninterrupted SSC. ${ }^{13,14}$

SSC improves breastfeeding outcomes, ${ }^{7,15}$ which has a significant influence on newborn and child survival. ${ }^{16,17} \mathrm{SSC}$

\footnotetext{
${ }^{1}$ School of Nursing, Texas Tech University Health Sciences Center, Lubbock, Texas.

${ }^{2}$ College of Nursing, University of Alabama in Huntsville, Huntsville, Alabama.

${ }^{3}$ Women and Children's Services, Baylor University Medical Center, Dallas, Texas.

${ }^{4}$ Perinatal Education, Women and Children's Services, Baylor University Medical Center, Dallas, Texas.
}

(c) Jeannette T. Crenshaw et al., 2019; Published by Mary Ann Liebert, Inc. This Open Access article is distributed under the terms of the Creative Commons Attribution Noncommercial License (http://creativecommons.org/licenses/by-nc/4.0/) which permits any noncommercial use, distribution, and reproduction in any medium, provided the original author(s) and the source are cited. 
also improves newborn cardiorespiratory stability, ${ }^{7,18}$ thermoregulation, ${ }^{15,19}$ glucose regulation, ${ }^{19}$ and newborn selfregulation, ${ }^{20}$ and reduces the stress of birth, while facilitating transition to extrauterine life. ${ }^{18,20}$ During immediate and uninterrupted SSC, newborns exhibit a species-specific sequence of nine instinctive behaviors that lead to finding the breast and suckling. ${ }^{21} \mathrm{SSC}$ reduces the duration of the third stage of labor, ameliorating the risk of postpartum hemorrhage, ${ }^{22}$ and may reduce maternal stress, anxiety, and pain during and after a cesarean. ${ }^{7}$

We found no evidence in published research or other literature on the physiologic outcomes of and maternal satisfaction with SSC that begins during cesarean surgery and continues, uninterrupted, for about 5 hours. We conducted this study to evaluate whether eliminating delays in SSC (e.g., waiting until a baby has been assessed in a warmer or waiting until the mother and baby are in recovery), eliminating interruptions (e.g., transfers from the operating room $[\mathrm{OR}]$ table to a recovery room [RR] bed; from a RR bed to a postpartum bed), and continuing SSC for extended durations (e.g., up to 5 hours) are feasible and safe.

\section{Aim}

The aim of our pilot study was to examine the feasibility and outcomes of immediate SSC that began during a cesarean surgery procedure, immediately following birth, and continued, uninterrupted, for about 5 hours, compared to SSC that began after a cesarean surgery procedure, once a mother is moved from the OR table. We described measures of maternal and newborn physiologic stability and stress; maternal satisfaction with their cesarean and their experience with $\mathrm{SSC}$; and exclusive breast milk feeding at hospital discharge.

\section{Materials and Methods}

SSC was defined as placing naked newborns on their mother's bare chest (chest to chest). The intraprofessional research team consisted of principal investigators from two academic settings, two nurse managers, a nurse educator, a nurse scientist, frontline nurses from labor and delivery, mother/baby, neonatal intensive care, and lactation services. Preparation and training of the research team included a review of informed consent procedures and skills demonstration and return demonstration on obtaining buccal salivary cortisol samples.

We used a quasiexperimental, time-interrupted design to describe maternal measures of physiologic stability (heart and respiratory rate, blood pressure, and oxygen saturation); newborn measures of physiologic stability (heart and respiratory rate, and oxygen saturation); maternal measures of comfort (nausea, vomiting, and pain); maternal and newborn stress (measured by salivary cortisol); maternal satisfaction with a cesarean and experience with SSC; and newborn exclusive breast milk feeding at hospital discharge, when SSC began during a cesarean (intervention) compared to after (standard care). We gathered relevant data, including time of birth and cord clamping, start time and duration of SSC, newborn gestational age, birth weight, and 1- and 5-minute Apgar scores.

\section{Setting and participants}

The setting was a 1,025-bed, non-for-profit, academic private medical center in the Southwest United States with an average of 4,700 births per year and a $27 \%$ overall cesarean rate. The study site was in the process of implementing the World Health Organization and United Nations International Children's Emergency Fund (UNICEF) ${ }^{23}$ Ten Steps to Successful Breastfeeding. The patient-payer mix was $54 \%$ private, $33 \%$ Medicaid, and $12 \%$ self-pay. Up to four elective, nonemergent cesareans were scheduled on Monday to Friday. Birth services included a level III neonatal intensive care.

Participants were recruited from a convenience sample of pregnant women who were having an elective, nonemergent cesarean on a data collection day and met the following criteria: 19-45 years of age; any gravida; a gestational age greater than or equal to 39 weeks; had a singleton gestation; spoke and read English; and were eligible to have SSC immediately following birth as determined by the health care professionals providing care at the time of birth. Three institutional review boards approved the study (two university Institutional Review Boards [IRBs] and the IRB at the study site).

We randomized participants to either the intervention $(n=20)$ or the standard care $(n=20)$ group by mothers opening an envelope identifying their assigned group after consenting to participate. The researchers who provided informed consent were blinded to the study group assignment during the consent process.

\section{Intervention group (Group 1)}

After the umbilical cord was cut, newborns were received by a registered nurse $(\mathrm{RN})$, placed on mother's bare upper chest, dried, and covered with a warmed infant blanket. During SSC, mothers and newborns were assessed and monitored as surgery continued. An RN stabilized (steadied) the newborn on mother's chest so that SSC continued without interruption during the transfer from the OR table to an RR bed. SSC continued, uninterrupted, until about 2 hours after admission to the New Family Center (NFC; mother/baby unit). Mothers in the intervention group who did not continue SSC until 2 hours after admission to the NFC did not meet study protocol and were withdrawn from the study.

\section{Standard care group (Group 2)}

Newborns were received by an $\mathrm{RN}$ and taken to a radiant warmer, assessed, swaddled in warm blankets, and held by either the father or another member of the family as surgery continued. SSC began in the OR, after mothers were transferred to an RR bed. SSC continued for as long as mothers wished. If a mother in the standard care group requested and received SSC during surgery, she was withdrawn from the study for not meeting study protocol.

\section{Study variables}

Dependent variables for the study included measures of physiological stability, stress, and maternal comfort; maternal satisfaction with her cesarean and experience with SSC; and newborn exclusive breast milk feeding status at hospital discharge. Maternal measures of physiologic stability were respiration and heart rate, oxygen saturation, temperature, blood pressure; and measures of comfort were nausea, vomiting, and pain. Stress was measured by salivary cortisol. We collected maternal measures at five points: (i) before 
transfer to the OR (preop); (ii) in the OR, about 20 minutes after birth; (iii) in the RR (about 1 hour after admission); (iv) in the NFC (about 1 hour after admission); and (v) in the NFC (about 2 hours after admission).

Infant measures of physiologic stability were respiration and heart rate, oxygen saturation, and temperature. Stress was measured by salivary cortisol. We collected infant measures at four points: (i) in the OR (about 20 minutes after birth); (ii) in the RR (about 1 hour after admission); (iii) in the NFC (about 1 hour admission); and (iv) in the NFC (about 2 hours after admission).

We also used salivary cortisol levels (SCLs), an indicator of plasma-free cortisol, as a biomarker (proxy) to assess level of stress. We collected maternal and newborn samples using the Salivary Cortisol Enzyme Immunoassay Kit by Salimetrics (2016). The samples were stored at $-65^{\circ} \mathrm{C}$ and sent to Salimetrics twice (midway and end of data collection) for analysis.

The Maternal Satisfaction with Cesarean survey was completed by mothers before discharge with help from a member of the research team. The survey, adapted (with permission) from a valid and reliable instrument developed by Morgan et al., ${ }^{24}$ consisted of a 10-question, seven-point agreement scale (strongly disagree to strongly agree). Examples of questions included the following: "In the OR, during the surgery, I was able to bond with my baby" and "I was able to nurse my baby after delivery." We added one open-ended response question: "What comments do you have about your experience with skin to skin with your baby during the first hour of your baby's life?'

Exclusive breast milk feeding status at hospital discharge was obtained from the infant's electronic health record.

Maternal demographic data were obtained before transfer to the OR. Newborn demographic data were obtained at birth, including date and time, time of first cry and umbilical cord clamping, gestational age, and gender.

\section{Analysis and statistical methods}

We collected data from July 5, 2016, through October 31, 2016. Members of the research team obtained and recorded data by hand on a data collection form. Data from the handwritten form were transcribed into an Excel spreadsheet and imported into SPSS v20.

Data were analyzed using descriptive statistics (frequency, mean, standard deviation [SD], and range), and parametric (independent samples $t$-test) and nonparametric hypothesis tests (Mann-Whitney U [MWU], Chi-square, and Fisher's exact).

\section{Results}

\section{Participants}

Women in the two groups were similar in age, race, education, previous pregnancies and live births, reason for cesarean, and feeding preference (Table 1). More than half of the women in each group reported having college, graduate, or postgraduate education. A total of $80 \%(n=16)$ in Group 1 and $90 \%(n=18)$ in Group 2 reported "exclusively breast milk" as their feeding preference. Newborns were similar in gestational age, gender, 1- and 5-minute Apgars, and birthweight (Table 1).

\section{Elapsed time from birth to SSC and duration of SSC}

Participants in both groups began SSC in the OR, but at different times, based on group randomization. For Groups 1 and 2, time of birth and time of cord clamp were the same. Women in Group 1 began SSC as soon as the umbilical cord was clamped. Women in Group 2 began SSC in the OR, following surgery, after mothers were moved from the OR table to the RR bed, and before transfer to the RR. The mean elapsed time from birth to SSC for Group $1(M=0.89 \mathrm{~min}-$ utes; SD 1.0; range $1-4 ; n=18$ ) compared to Group 2 $(M=46$; SD 11.8; range $31-72$ minutes; $n=20)$ was significantly different (MWU 360; $n=38 ; p=0.000$ ) and shorter (Table 2).

\section{Measures of physiologic stability}

Maternal physiologic stability-overall. Maternal measures of physiologic stability (respiratory and heart rate, blood pressure, temperature, and oxygen saturation) were aggregated across time (five serial observations) and tested for differences. The mean maternal heart rate for Group 1 $(M=87$; SD 16.2; range 54-150; $n=100)$ compared to Group $2(M=81$; SD 13.9 ; range $52-118 ; n=100)$ was significantly different (MWU 3,890; $n=200 ; p=0.007$ ) and higher. The mean maternal oxygen saturation for Group $1(M=97$; SD 1.6; range 93-100; $n=98)$ compared to Group $2(M=98$; SD 1.6; range 94-100; $n=99$ ) was significantly different (MWU 5,687; $n=197 ; p=0.034$ ) and lower. We found no other statistically significant differences at a $95 \%$ confidence level (Table 2).

Maternal physiologic stability-serial. We tested for differences in mean rank between Group 1 and Group 2 for measures of physiologic stability at each of the five serial observations. The mean maternal oxygen saturation in the OR for Group $1(M=97$; SD 1.8 ; range 94-100; $n=20)$ compared to Group $2(M=98 ;$ SD 1.6 ; range $96-100 ; n=20)$ was significantly different (MWU 288; $n=40 ; p=0.014$ ) and lower. We found no other statistically significant differences at $95 \%$ confidence (Table 3 ).

Newborn physiologic stability-overall. Newborn measures of physiologic stability (respiratory and heart rate, temperature, and oxygen saturation) were aggregated across time (five serial observations) and tested for differences. We found no significant difference at $95 \%$ confidence between Group 1 and 2 (Table 2).

Newborn physiologic stability-serial. We tested for differences in mean rank between Group 1 and Group 2 at each of the four serial observations. Only temperature in the OR and heart rate in the NFC 2 hours after admission were statistically different. The mean newborn temperature in the OR for Group $1(M=98.9$; SD 0.6 ; range $98-100 ; n=20)$ compared to Group $2(M=99.4$; SD 0.7 ; range $98-101 ; n=20)$ was significantly different (MWU 280.5; $n=40 ; p=0.029$ ) and lower. The mean newborn heart rate in the NFC 2 hours after admission for Group $1(M=131$; SD 8.5; range $115-$ $150 ; n=20)$ compared to Group $2(M=125$; SD 11.9; range $100-156 ; n=20$ ) was significantly different (MWU 125.5; $n=40 ; p=0.044$ ) and higher. We found no other statistically significant difference at $95 \%$ confidence (Table 3 ). 
Table 1. Maternal and Newborn Characteristics in Participants Randomized to Have Immediate, Uninterrupted Skin-to-Skin Care Beginning During Medically Uncomplicated Cesarean Surgery (Group 1, Intervention) or Beginning After Surgery, in the Operating Room (Group 2, Standard Care)

\begin{tabular}{|c|c|c|c|c|c|}
\hline & \multicolumn{2}{|c|}{ Group 1 (intervention) $\mathrm{n}=20$} & \multicolumn{2}{|c|}{ Group 2 (standard care) $\mathrm{n}=20$} & \multirow{2}{*}{$\frac{\text { Test/Sig }}{M W U \text { test }}$} \\
\hline & & $M(S D)$ & & $M(S D)$ & \\
\hline & $\mathrm{n}(\%)$ & Range & $\mathrm{n}(\%)$ & Range & $\operatorname{Sig}(\mathrm{p})$ \\
\hline \multicolumn{6}{|l|}{ Maternal characteristics } \\
\hline Age (years) & $20(100)$ & $\begin{array}{l}33(3.3) \\
28-40\end{array}$ & $20(100)$ & $\begin{array}{l}33(5.1) \\
24-45\end{array}$ & $\begin{array}{c}p=0.924 \\
\mathrm{~ns}\end{array}$ \\
\hline Race & $20(100)$ & & $20(100)$ & & \\
\hline African American & $2(10)$ & - & $2(10)$ & - & - \\
\hline Asian & $1(5)$ & - & $1(5)$ & - & - \\
\hline Caucasian & $15(75)$ & - & $11(55)$ & - & - \\
\hline Hispanic & $2(10)$ & - & $6(30)$ & - & - \\
\hline Education & $20(100)$ & & $20(100)$ & & \\
\hline High school & $2(10)$ & - & $4(20)$ & - & - \\
\hline Career/technical training & $1(5)$ & - & $1(5)$ & - & - \\
\hline College & $10(50)$ & - & $10(50)$ & - & - \\
\hline Graduate school & $5(25)$ & - & $5(25)$ & - & - \\
\hline Post graduate & $2(10)$ & - & - & - & - \\
\hline Previous pregnancies & $20(100)$ & $\begin{array}{l}2.5(2.0) \\
0-7\end{array}$ & $20(100)$ & $\begin{array}{l}2.5(1.2) \\
1-5\end{array}$ & $\begin{array}{c}p=0.606 \\
\mathrm{~ns}\end{array}$ \\
\hline \multirow[t]{2}{*}{ Previous live births } & $20(100)$ & $1.5(1.3)$ & $20(100)$ & $1.3(0.8)$ & $p=0.805$ \\
\hline & & $0-4$ & & $0-3$ & ns \\
\hline Reason for cesarean & $20(100)$ & & $20(100)$ & & \\
\hline Breech & $4(20)$ & - & $2(10)$ & - & - \\
\hline Macrosomia & $1(5)$ & - & - & - & - \\
\hline Previous uterine surgery & $1(5)$ & - & - & - & - \\
\hline Repeat cesarean & $14(70)$ & - & $18(90)$ & - & - \\
\hline Feeding preference & $20(100)$ & & $20(100)$ & & \\
\hline Exclusively breast milk & $16(80)$ & - & $18(90)$ & - & - \\
\hline Exclusively pumping & $1(5)$ & - & - & - & - \\
\hline Formula & $1(5)$ & - & - & - & - \\
\hline Both & $2(10)$ & - & $1(5)$ & - & - \\
\hline Undecided & - & - & $1(5)$ & - & - \\
\hline \multicolumn{6}{|l|}{ Newborn characteristics } \\
\hline \multirow[t]{2}{*}{ Gestational age (weeks/days) } & $19(100)$ & $39.3(0.3)$ & $19(100)$ & $39.4(0.5)$ & $p=0.452$ \\
\hline & & $39.0-40.0$ & & $39.0-40.1$ & ns \\
\hline Gender & $20(100)$ & & $19(100)$ & & \\
\hline Male & $11(55)$ & - & $11(58)$ & - & - \\
\hline Female & $9(45)$ & - & $8(42)$ & - & - \\
\hline \multirow{2}{*}{$\begin{array}{l}\text { Gender not recorded } \\
\text { Apgar (1 minute })\end{array}$} & - & - & $1(5)$ & - & - \\
\hline & $20(100)$ & $\begin{array}{l}8.3(0.5) \\
8-9\end{array}$ & $20(100)$ & $\begin{array}{l}8.4(0.8) \\
6-9\end{array}$ & $p=\underset{n s}{0.423}$ \\
\hline Apgar (5 minutes) & $20(100)$ & $9.0(0.0)$ & $20(100)$ & $8.9(0.2)$ & $p=0.317$ \\
\hline \multirow{2}{*}{ Birth weight (g) } & $20(100)$ & $\begin{array}{c}9-9 \\
3.716(442)\end{array}$ & $5(100)$ & $\begin{array}{c}8-9 \\
3.724(290)\end{array}$ & $\begin{array}{c}\mathrm{ns} \\
p=1.000\end{array}$ \\
\hline & & $2,692-4,690$ & & $3,450-4,110$ & ns \\
\hline
\end{tabular}

Questions regarding race/ethnicity and education were based on format from the study site electronic health record.

ns, not statistically significant at the $95 \%$ confidence of probability $(p>0.05)$; SD, standard deviation; MWU, Mann-Whitney U.

\section{Measures of stress (salivary cortisol)}

Maternal salivary cortisol-overall. Maternal salivary cortisol values were aggregated across time (five serial observations) and tested for differences. The mean maternal salivary cortisol for Group $1(M=0.496$; SD 0.45 ; range $0.06-2.7 ; n=87)$ compared to Group $2(M=0.701$; SD 1.06, range $0.14-2.96 ; n=88$ ) was significantly different (MWU $4,812.5 ; n=175 ; p=0.003$ ) and lower.

Maternal salivary cortisol-serial. We tested for differences in maternal salivary cortisol between Group 1 and Group
2 at each serial observation and found significant differences in the OR and the NFC. The mean maternal SCL in the OR for Group $1(M=0.85$; SD 0.56; range 0.36-2.5; $n=15)$ compared to Group $2(M=1.3$, SD 0.66 ; range $0.51-2.7 ; n=15)$ was significantly different (MWU 168.0; $n=30 ; p=0.021$ ) and lower. The mean maternal salivary cortisol in the NFC 2 hours after admission for Group $1(M=0.3$; SD 0.31; range 0.06-1.2; $n=19)$ compared to Group $2(M=0.59$; SD 0.69 ; range 0.14 $2.7 ; n=19$ ) was significantly different (MWU 261.5; $n=38$; $p=0.017$ ) and lower. No significant differences between groups were found at preop, RR, and 1 hour after NFC admission. 
Table 2. Overall Measures in Participants Randomized to Have Immediate, Uninterrupted Skin-to-Skin Care That Began During Medically Uncomplicated Cesarean Surgery (Group 1, Intervention) or After Surgery, in the Operating Room (Group 2 Standard Care)

\begin{tabular}{|c|c|c|c|c|c|}
\hline \multicolumn{3}{|c|}{ Maternal } & \multicolumn{3}{|c|}{ Newborn } \\
\hline & $\begin{array}{l}\text { M (SD) } \\
\text { Range }\end{array}$ & Test Sig (p) $M W U$ & & $\begin{array}{l}\text { M (SD) } \\
\text { Range }\end{array}$ & Test Sig (p) $M W U$ \\
\hline $\begin{array}{l}\text { HR } \\
\qquad \text { G1 } n=100 \\
\text { G2 } n=100\end{array}$ & $\begin{array}{c}87(16.2) \\
54-150 \\
81(13.9)\end{array}$ & $p=0.007$ & $\begin{array}{c}\text { HR } \\
\text { G1 } n=80 \\
\text { G2 } n=80\end{array}$ & $\begin{array}{c}139(14.8) \\
110-184 \\
138(17.8)\end{array}$ & $\begin{array}{c}p=0.535 \\
\mathrm{~ns}\end{array}$ \\
\hline $\begin{array}{l}\text { RespR } \\
\text { G1 } n=100 \\
\text { G2 } n=100\end{array}$ & $\begin{array}{c}52-118 \\
18(2.0) \\
12-24 \\
18(1.9) \\
14-24\end{array}$ & $\begin{array}{c}p=0.399 \\
\mathrm{~ns}\end{array}$ & $\begin{array}{c}\text { RespR } \\
\text { G1 } n=80 \\
\text { G2 } n=80\end{array}$ & $\begin{array}{l}100-172 \\
49(11.2) \\
32-88 \\
49(9.7) \\
16-72\end{array}$ & $\begin{array}{c}p=0.812 \\
\mathrm{~ns}\end{array}$ \\
\hline $\begin{array}{l}\text { RespR } \\
\text { G1 } n=100 \\
\text { G2 } n=100\end{array}$ & $\begin{array}{c}18(2.0) \\
12-24 \\
18(1.9) \\
14-24\end{array}$ & $\begin{array}{c}p=0.399 \\
\mathrm{~ns}\end{array}$ & & & $\begin{array}{c}p=0.812 \\
\mathrm{~ns}\end{array}$ \\
\hline $\begin{array}{l}\text { MABP } \\
\qquad \text { G1 } n=100 \\
\text { G2 } n=100\end{array}$ & $\begin{array}{c}92(12.1) \\
65-123 \\
91(11.8) \\
55-120\end{array}$ & $\begin{array}{c}p=0.606 \\
\text { ns }\end{array}$ & & & \\
\hline $\begin{array}{l}\mathrm{SC} \\
\qquad \mathrm{G} 1 n=87 \\
\mathrm{G} 2 n=88\end{array}$ & $\begin{array}{c}0.496(0.45) \\
0.06-2.7 \\
0.701(1.06)\end{array}$ & $p=0.003$ & $\begin{array}{c}\mathrm{SC} \\
\mathrm{G} 1 \quad n=68 \\
\mathrm{G} 2 n=73\end{array}$ & $\begin{array}{c}1.42(1.1) \\
0.1-4.6 \\
1.5(1.6)\end{array}$ & $\begin{array}{c}p=0.549 \\
\mathrm{~ns}\end{array}$ \\
\hline $\begin{array}{l}\text { SPO2 } \\
\text { G1 } n=98 \\
\text { G2 } n=99\end{array}$ & $\begin{array}{l}0.14-2.96 \\
97(1.6) \\
93-100 \\
98(1.6) \\
94-100\end{array}$ & $p=0.034$ & $\begin{array}{c}\text { SPO2 } \\
\text { G1 } n=79 \\
\text { G2 } n=89\end{array}$ & $\begin{array}{l}0.1-9.7 \\
97(3.1) \\
81-100 \\
97(2.3) \\
90-100\end{array}$ & $p=\underset{n s}{0.526}$ \\
\hline $\begin{array}{l}\text { Temp } \\
\text { G1 } n=100 \\
\text { G2 } n=100\end{array}$ & $\begin{array}{c}98(0.37) \\
97-99 \\
98(0.42) \\
97-09\end{array}$ & $p=\underset{\mathrm{ns}}{0.150}$ & $\begin{array}{c}\text { Temp } \\
\text { G1 } n=80 \\
\text { G2 } n=80\end{array}$ & $\begin{array}{l}99(1.0) \\
96-101 \\
99(1.0)\end{array}$ & $p=0.933$ \\
\hline $\begin{array}{l}\text { Pain Y/N } \\
\qquad \begin{array}{l}\text { G1 } n=98 \\
\text { G2 } n=100\end{array}\end{array}$ & $\begin{array}{l}\text { Yes/No } \\
28 \mathrm{Y} / 70 \mathrm{~N} \\
28 \mathrm{Y} / 72 \mathrm{~N}\end{array}$ & $\begin{array}{c}\chi^{2} \text { Fisher's exact test } \\
\qquad \begin{array}{c}p=0.527 \\
\mathrm{~ns}\end{array}\end{array}$ & $\begin{array}{c}\text { EBMF } \\
\text { G1 } n=19 \\
\text { G2 } n=20\end{array}$ & $\begin{array}{l}\text { No } 5 / \text { Yes } 14 \\
\text { No } 2 / \text { Yes } 18\end{array}$ & 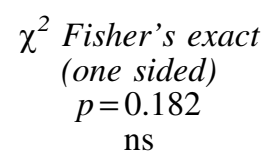 \\
\hline $\begin{array}{l}\text { Pain Scale } \\
\qquad \begin{array}{l}\text { G1 } n=93 \\
\text { G2 } n=89\end{array}\end{array}$ & $\begin{array}{c}\text { Scale } 0-7 \\
1.1(1.9) \\
0-7 \\
1.3(1.8) \\
0-6\end{array}$ & $\begin{array}{c}\text { Test Sig (p) } \\
\text { MWU } \\
p=0.589 \\
\text { ns }\end{array}$ & $\begin{array}{l}\text { Birth to SSC } \\
\text { elapsed minutes } \\
\text { G1 } n=18 \\
\text { G2 } n=20\end{array}$ & $\begin{array}{c}0.89(1.0) \\
0-4 \\
46(11.8) \\
31-72\end{array}$ & $\begin{array}{l}\text { MWU test } \\
\quad \text { Sig }(p) \\
\\
p=0.000\end{array}$ \\
\hline $\begin{array}{l}\text { Nausea } \\
\qquad \text { G1 } n=99 \\
\text { G2 } n=99\end{array}$ & $\begin{array}{l}\text { Yes/No } \\
4 \mathrm{Y} / 95 \mathrm{~N} \\
6 \mathrm{Y} / 93 \mathrm{~N}\end{array}$ & $\begin{array}{c}\chi^{2} \text { Fisher's } \\
\text { exact test } \\
p=0.374 \\
\text { ns }\end{array}$ & $\begin{array}{l}\text { SSC duration } \\
\qquad \text { G1 } n=9 \\
\text { G2 } n=9\end{array}$ & $\begin{array}{c}301(22.5) \\
272-341 \\
126(50) \\
58-230\end{array}$ & $p=0.000$ \\
\hline $\begin{array}{l}\text { Vomiting } \\
\qquad \text { G1 } n=99 \\
\text { G2 } n=100\end{array}$ & $\begin{array}{l}\text { Yes/No } \\
0 \mathrm{Y} / 99 \mathrm{~N} \\
2 \mathrm{Y} / 98 \mathrm{~N}\end{array}$ & $\begin{array}{c}\chi^{2} \text { Fisher's exact test } \\
p=0.251 \\
\mathrm{~ns}\end{array}$ & & & \\
\hline $\begin{array}{l}\text { Satisfaction survey } \\
\qquad \begin{array}{l}\text { G1 } n=20 \\
\text { G2 } n=20\end{array}\end{array}$ & $\begin{array}{c}\text { Higher }=\text { more } \\
55(3.5) \\
48-60 \\
50(8.2) \\
34-60\end{array}$ & $\begin{array}{c}\text { Summated score } \\
\text { t-test } \\
p=0.015 \\
\text { CI }(1.1-9.2) \\
\text { Normally distributed }\end{array}$ & & & \\
\hline
\end{tabular}

ns, not statistically significant at the $95 \%$ confidence of probability $(p>0.05)$; MABP, mean arterial blood pressure: (systolic-diastolic); SC, salivary cortisol; Temp, temperature, normalized ( -1 rectal, +1 axillary); MWU, Mann-Whitney U test of independent samples mean ranks; SSC, skin-to-skin care; HR, heart rate; RespR, respiratory rate; SPO2, oxygen saturation; Pain scale, $0-10(0=$ no pain and $10=$ worst possible pain); EBMF, exclusive breast milk feeding at hospital discharge; satisfaction survey, maternal satisfaction with cesarean and SSC; $\mathrm{SD}$, standard deviation; CI, confidence interval. 


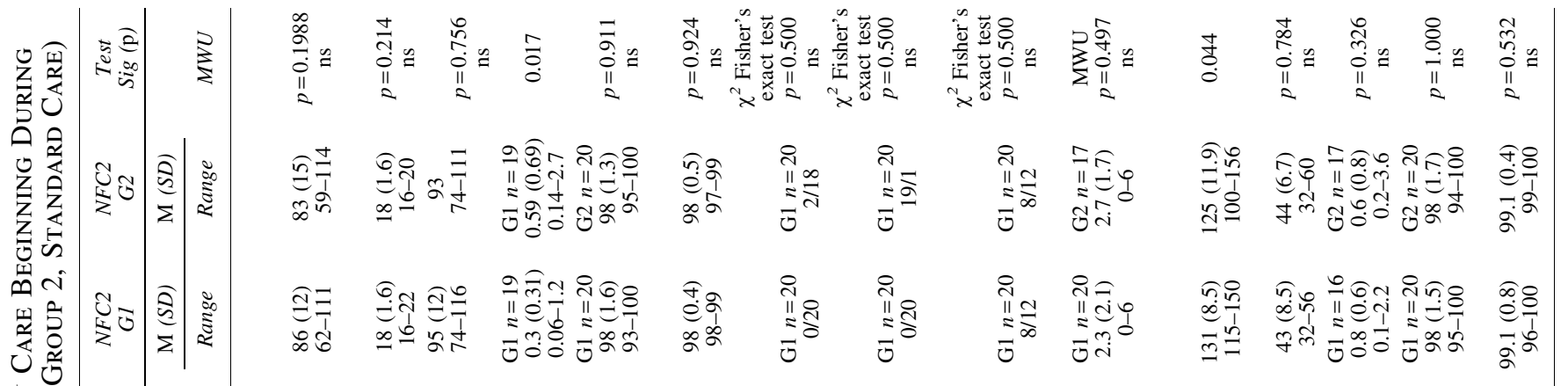

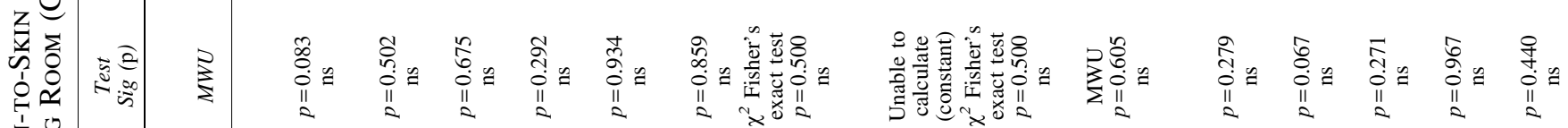

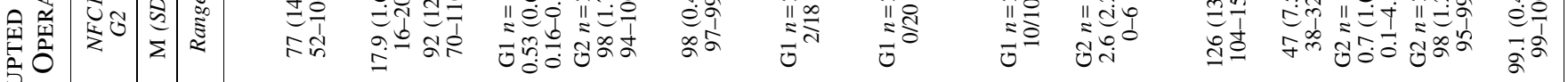

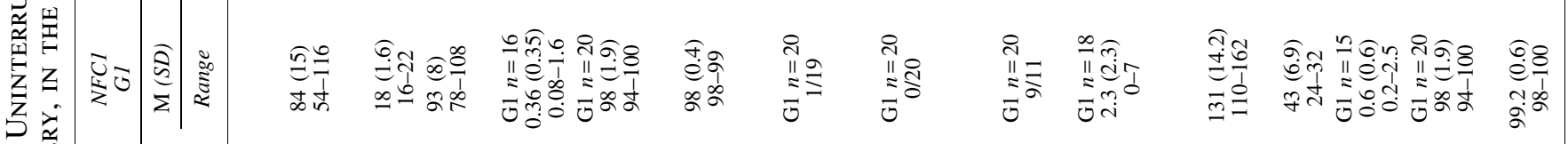

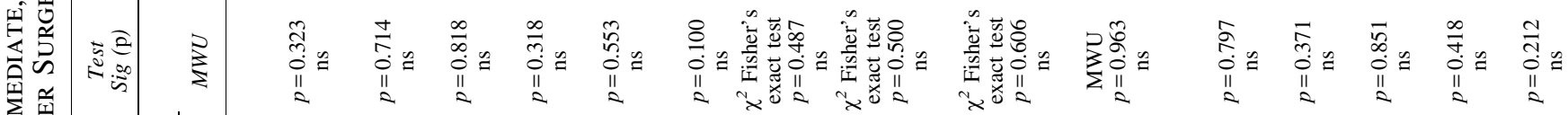

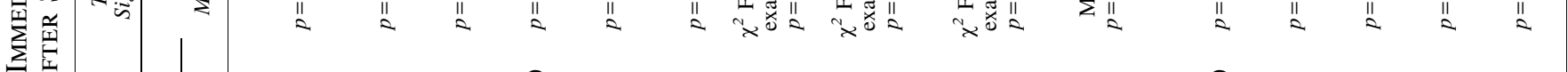

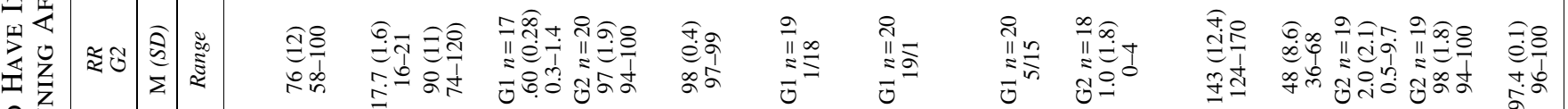

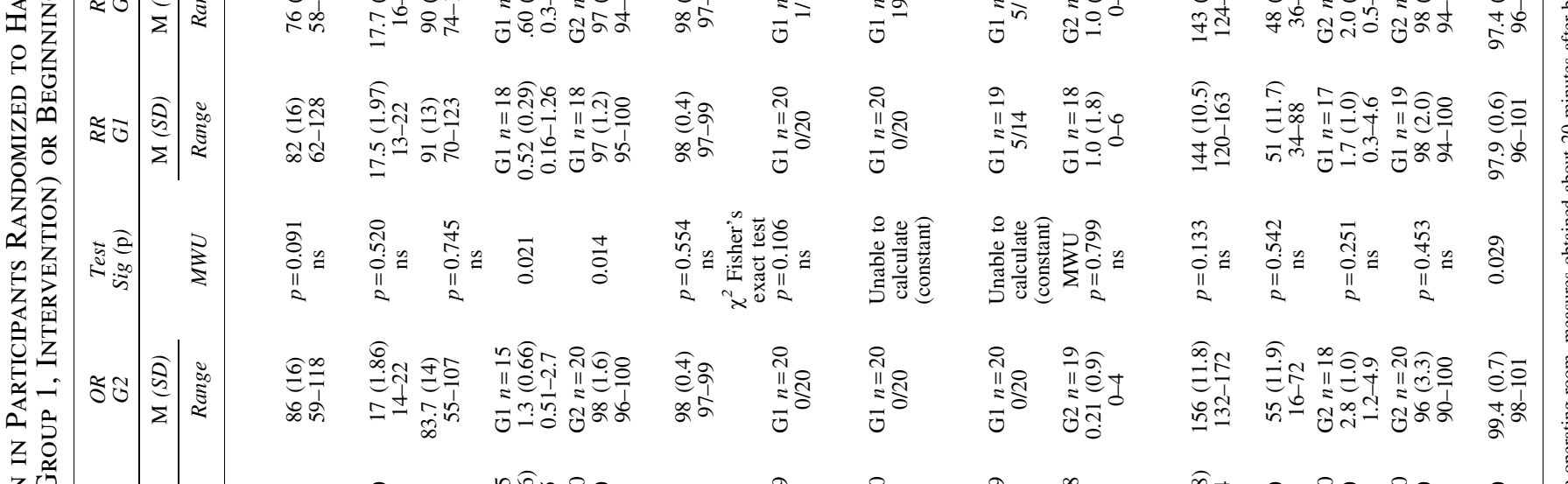

Z

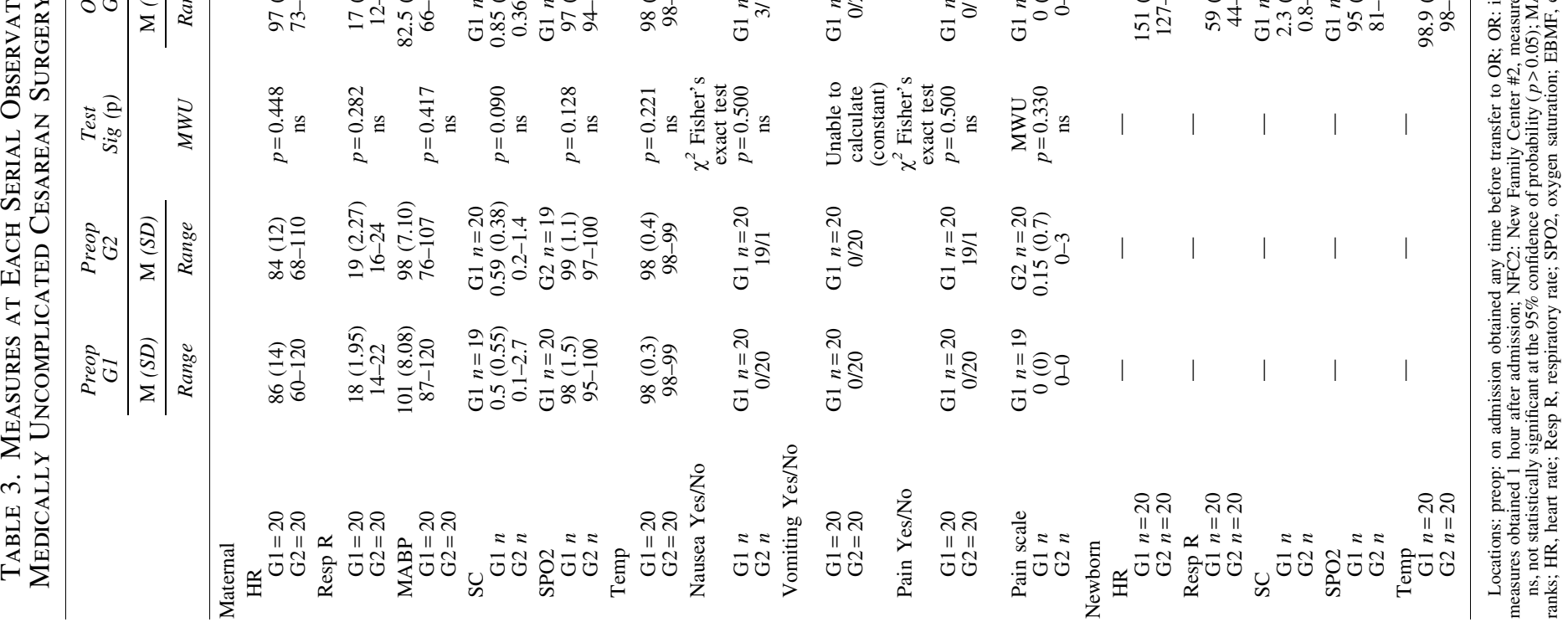


Newborn salivary cortisol-overall. Newborn salivary cortisol values were aggregated across time (five serial observations) and tested for differences. We found no significant difference for Group 1 compared to Group 2 (MWU $2,337.0 ; n=141 ; p=0.549$; Table 2 ). We tested for differences in newborn salivary cortisol between Group 1 and Group 2 at each serial observation and found no significant differences (Table 2).

\section{Measures of maternal comfort}

Overall differences. For maternal measures of comfort (nausea yes/no, vomiting yes/no, pain yes/no, and pain), we found no significant differences overall or for each serial observation at $95 \%$ confidence level between Group 1 and 2 (Tables 2 and 3).

\section{Measures of maternal satisfaction with cesarean and experience with SSC}

The summative survey score was calculated from the 10question, 7-point Likert agreement scale $(0=$ strongly disagree and $6=$ strongly agree) with a possible range of $0-60$. The mean of the summative survey score for participant satisfaction in Group 1 (55.05; $n=20$; SD 3.49; range 48-60) was significantly different and higher compared to Group 2 (49.9; $n=20$; SD 8.17; range 34-60; independent samples $t$ test; $n=40$; mean difference $5.1 ; p=0.015$; equal variance not assumed; Table 3). We compiled responses to the openended question ("What comments do you have about your experience with skin to skin with your baby during the first hour of your baby's life? Table 4) and used NVivo v11 for thematic analysis of the responses (Table 4). Text analysis demonstrated more "moderately positive" and "very positive" sentiment in Group 1 comments compared to Group 2. The word vine for Group 1 displayed a focus on the relationship (baby) and for Group 2, a focus on the procedure and process of SSC (skin) (Fig. 1).

\section{Newborn exclusive breast milk feeding at hospital discharge}

We found no statistically significant difference in the proportion of exclusive breast milk feeding at hospital discharge in Group $1(70 \%$ yes $=14 ; n=19)$ compared to Group $2(90 \%$ yes $=18 ; n=20$; one-sided Fisher's exact test, $p=0.182$; Table 3).

\section{Discussion}

To our knowledge, this is the first analysis of SSC outcomes in participants having a medically uncomplicated cesarean who were randomized, regardless of feeding preference, to either immediate and uninterrupted SSC for an extended duration or to standard care. We used this quasiexperimental design to study whether SSC could feasibly and safely begin immediately following cesarean birth (during surgery) and continue uninterrupted for about 5 hours. Our results suggest that SSC is feasible and safe when it begins immediately, without an assessment in a radiant warmer; that SSC can safely continue during transfer from an OR table to an RR bed and from an RR bed to a postpartum room bed; and that SSC can be maintained safely for extended durations.
What makes our study unique is that, although all participants had SSC for at least 2 hours, Group 1 began SSC less than a minute after the umbilical cord was cut and continued uninterrupted for 5 hours ( 2 hours after admission to the NFC). Group 2 waited to begin SSC until after surgery (about 50 minutes). In other studies of SSC and cesarean surgery, participants were not randomized ${ }^{25}$; SSC did not begin until after an assessment in a radiant warmer ${ }^{26-30}$; duration of uninterrupted SSC was $<1$ hour ${ }^{1,26,28,31}$; women who did not have SSC were included ${ }^{32}$; SSC was interrupted for transfers ${ }^{26,27}$; and/or only women who planned to breastfeed were included. $^{28,31}$

Although elapsed time from birth to SSC and duration were significantly shorter for Group 1 compared to Group 2 (Table 3), we did not find a difference in exclusive breast milk feeding at hospital discharge. Our small sample size and our inclusion of participants who did not plan to breastfeed may have precluded finding a difference. In addition, women in both groups were exposed to the World Health Organization/UNICEF's ${ }^{23}$ Ten Steps to Successful Breastfeeding (Ten Steps). Exposure to increasing numbers of the Ten Steps has a dose-response effect on improving breastfeeding outcomes, ${ }^{2}$ which may have ameliorated the impact of the delay in initiating SSC experienced by Group 2 participants.

Bramson et al. ${ }^{32}$ reported that early initiation and long durations of SSC compared to short had a dose-response effect on breastfeeding. Their large multisite study included nonrandomized participants who had vaginal and cesarean birth, who had no SSC, and who had short durations (1-15 minutes) as well as durations of up to 1-3 hours. We did not find a dose-response effect, but that may be explained, in part, because our study was limited in size, only included participants having cesarean surgery, and all participants had SSC for extended durations (Group 1, 5 hours, and Group 2, 2 hours).

One of the barriers to immediate SSC during cesarean surgery is health professionals' concern that mothers may not be able to maintain their newborn's temperature during SSC, particularly in a cold OR. ${ }^{16,30,33}$ Although we did not alter the temperature in the ORs for this study (which averaged $68.48^{\circ} \mathrm{F}$ ), we found no overall significant difference in temperature between groups for mothers or newborns. In serial observations, newborn temperature in the OR for Group 1 compared to Group 2 was lower; however, physiologic measures in both groups (overall and at each of the serial observations) were within a range of what is considered normal. Also, no participants were required to withdraw from the study due to concerns about physiologic stability. Our findings help to alleviate the concerns about risks of newborn hypothermia with SSC during and after cesarean surgery.

Although we found a significant difference between groups in maternal oxygen saturation (Table 2), we believe the difference is not clinically significant, as the results were within normal limits and we did not find a corresponding significant difference in respiratory rate. While we found a significant difference in overall mean heart rate for Group 1 (87) compared to Group 2 (81), more research may be needed to explain influences of the autonomic nervous system on maternal heart rate. No participant was required to withdraw from the study due to adverse clinical symptoms.

Our findings on maternal stress (overall and serial) suggest that SSC reduces maternal stress during surgery and 


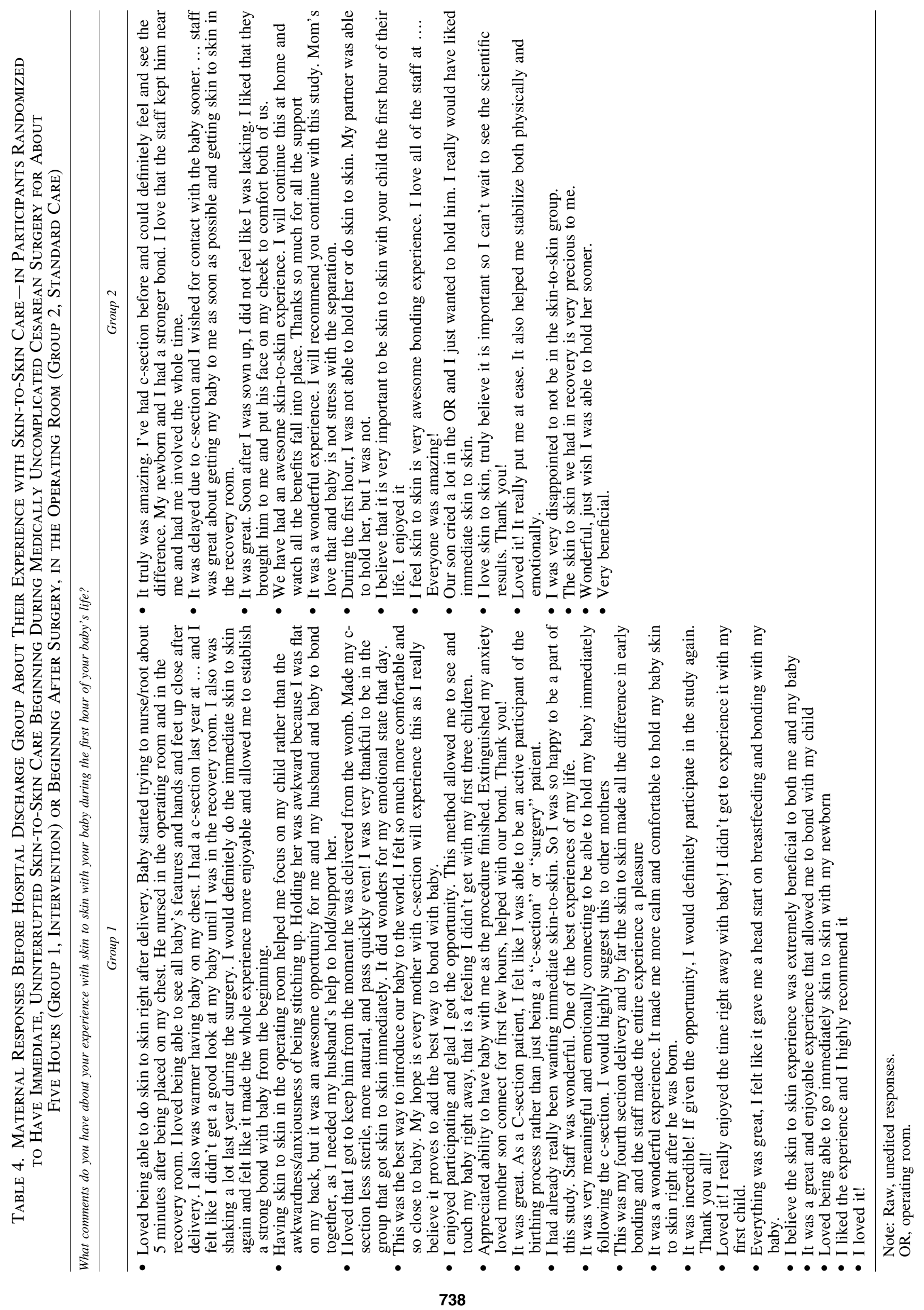


may have a cumulative stress-reducing effect that continues, while mother and newborn are skin to skin. Not only were maternal SCLs in Group 1 significantly lower than Group 2, SCLs in Group 1 continued to decline during the 5 hours of SSC.

Although we found no difference in overall and serial newborn cortisol levels, a "normal" for newborn SCLs has yet to be identified. In addition, accurate newborn SCLs are difficult to obtain and accurately measure due to presence of amniotic fluid at birth, and milk from feedings.

Our results also suggest that SSC does not negatively influence nausea, vomiting, and pain in women having uncomplicated cesareans. We found no difference (overall or serial) between groups for these measures of maternal comfort.

Group 1 participants were significantly more satisfied with their cesarean birth compared to Group $2(p=0.015$; Table 3$)$. These findings are consistent with other researchers who studied maternal satisfaction with SSC during surgery. ${ }^{25,34} \mathrm{We}$ found that women in Group 1 were more frequently "moderately positive" and "very positive" about the experiences of SSC compared to Group 2 (Fig. 1). Because SSC for the Group 1 continued for an average of 5 hours, this result suggests that duration of SSC positively influences maternal satisfaction and might have a dose-response effect.

We reflected on the qualitative themes displayed in the word cloud/vine (Fig. 1) and the possible meaning. An influencing variable is that women knew before the start of surgery, that they were to receive or not receive SSC. Women also knew that if they were randomized to Group 2, they would wait for SSC until after surgery (standard care). That may explain why women in Group 2 were more focused on the process of SSC, which was withheld until after surgery. They may have felt loss or disappointment that they were not randomized to Group 1. In addition, women in Group 1, who knew they would have immediate SSC, may have felt relieved and free to focus on their baby and their relationship. These findings all underscore the immense value women place on immediate and continuous interaction with their newborn and suggest that health care professionals should strive to eliminate all unnecessary delays in initiating SSC.

\section{Limitations and recommendations}

Generalizability is limited due to the small sample size (20 per group) at a single site, despite the quasiexperimental design and participant randomization. However, the sample size is appropriate for pilot and feasibility studies. Limitations also include the high percentage of college-prepared women in the study.

Data collection and manual documentation were difficult and time intensive. The extensive data collection form (more than 145 data fields) and the 12-member interprofessional research team and the multiple serial observation locations (preop, OR, RR, NFC1, and NFC2) were barriers to ensuring all data were collected and collected consistently. For example, we obtained only 9 values out of 20 for the variable, duration of SSC for each group, to compare mean duration. These data were missing because the location on the data collection form was difficult to find. We had several birth weights missing in Group 1 because written instructions on the data collection form were not clear, and birth weight normally was not obtained 2 hours after admission to post- partum (as required for Group 1). We recommend piloting a data form and reducing data collection points for future studies.

Newborn salivary cortisol samples were difficult to obtain. Scant evidence is available in the literature to provide guidance. Obtaining salivary cortisol samples was a new procedure that each member of the research team had to learn. The difficulty in obtaining salivary cortisol samples and the small sample size resulted in inclusive results.

Experts recommend uninterrupted SSC, which, in our clinical experience, is interpreted as a newborn remaining skin to skin with mother. We recommend that future researchers also consider undisturbed SSC in their methods. We recommend considering an alternative biomarker for newborn stress instead of SCLs to avoid inserting swabs in newborns' mouths during a period when breastfeeding behaviors are developing. Also, since newborns normally breastfeed on and off continuously during the hours after birth, we were unable to identify collection times that did not disturb SSC (e.g., SCLs and oxygen saturation).

We had some barriers in obtaining newborn oxygen saturations when babies were not under a radiant warmer. The Labor and Delivery unit had one type of portable oxygen saturation device and the NFC, another. More practice with the devices would have enhanced the accuracy of the results.

Future researchers might consider using thermography to obtain skin temperatures (an index of body surface temperature), in addition to or instead of axillary temperatures (an index of core temperatures). According to Kelly et al., ${ }^{35, \text { p. } 610}$ "skin temperatures represent a balance of heat that is lost or gained from the skin's exterior surface through interaction with external and environmental factors such as SSC." Using a thermography camera would prevent disturbing a newborn while having SSC. In addition, future researchers might consider measuring carbon dioxide levels, which could indicate if a difference in oxygen saturation was related to breathing patterns (e.g., hyperventilation).

To facilitate implementing SSC during cesarean surgery, we recommend using Healthy Children Project's Skin-toSkin Algorithm (HCP-S2S-IA), which now has been tested in three countries. ${ }^{9,10}$ The HCP-S2S-IA is a color-coded process map, which illustrates best practices (green), practices that require review (yellow), and practices that prevent (red) immediate, and uninterrupted, SSC in the first hour of life.

\section{Conclusion/Implications}

SSC is a simple, low-cost intervention that can have significant impact on immediate and future maternal and newborn outcomes. Our study showed that it is feasible to provide immediate and uninterrupted SSC for mothers during and after cesarean surgery. We found no untoward effects on maternal (respiratory and heart rate, blood pressure, temperature, and oxygen saturation) or newborn (respiratory and heart rate, temperature, and oxygen saturation) measures of physiologic stability. Moreover, women strongly preferred immediate SSC. This simple, patient-centered approach can help normalize the birth experience following surgery, enhance bonding, reduce maternal stress, and support breastfeeding. Considering the known maternal and newborn benefits of SSC and the absence of negative outcomes, health professionals have a responsibility to advocate for this 

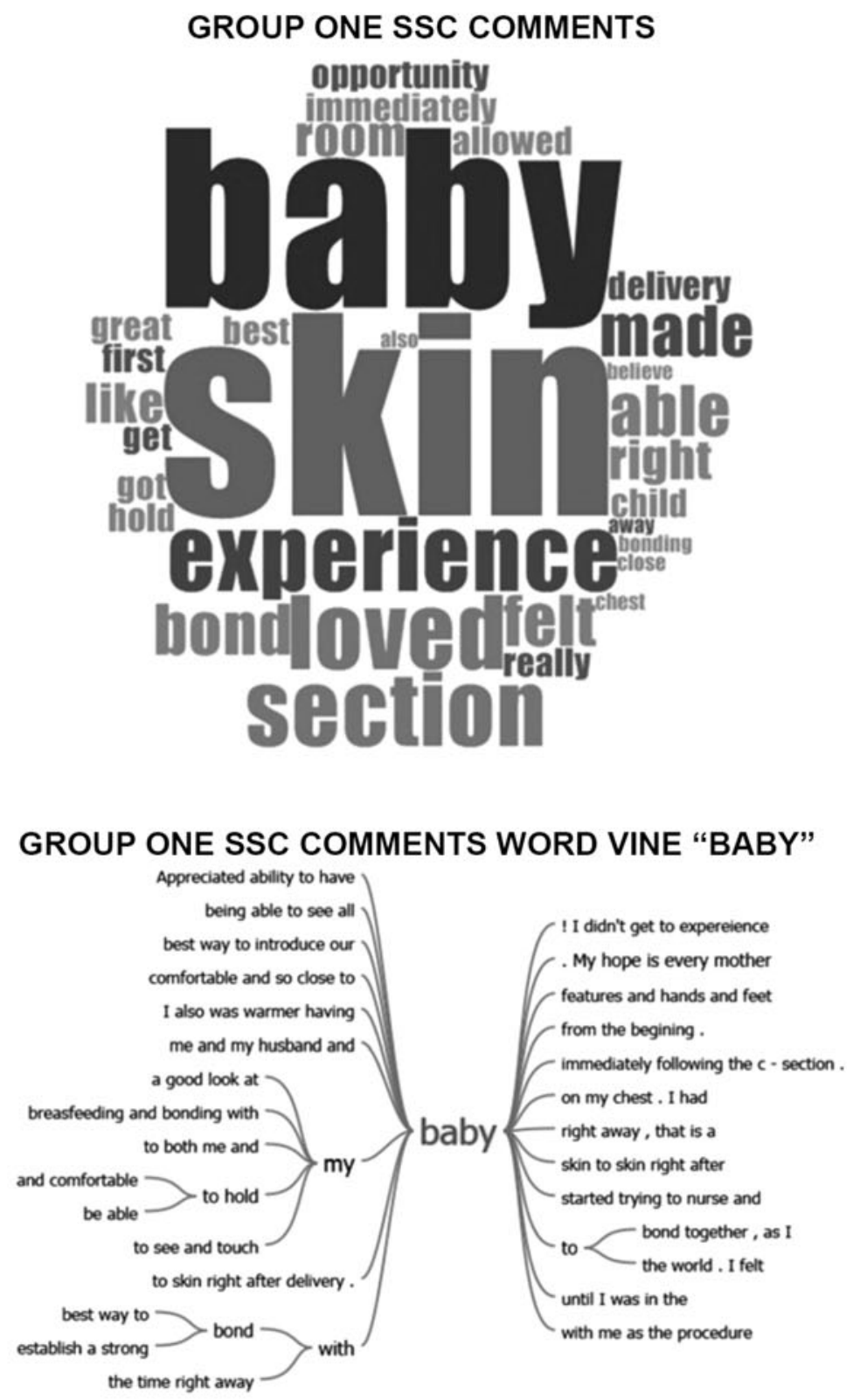

GROUP ONE SSC SENTIMENTS

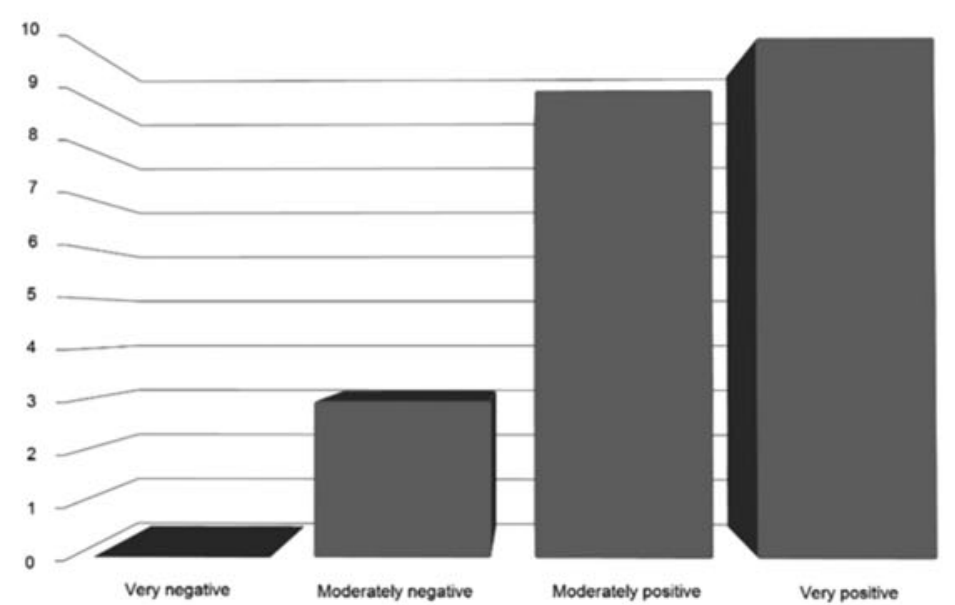

FIG. 1. NVivo thematic analysis of maternal responses before hospital discharge group about their experience with SSC - in participants randomized to have immediate, uninterrupted SSC beginning during medically uncomplicated cesarean surgery for about 5 hours (Group 1, intervention) or beginning after surgery, in the operating room (Group 2, standard care) SSC, skin-to-skin care. 


\section{GROUP TWO SSC COMMENTS}

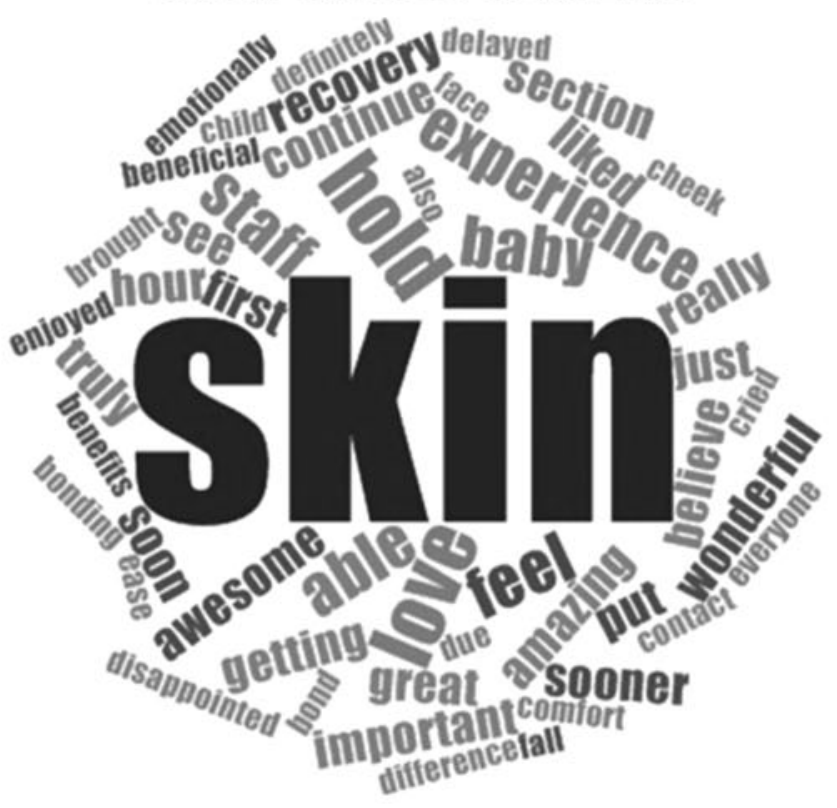

\section{GROUP TWO SSC COMMENTS WORD VINE "SKIN"}

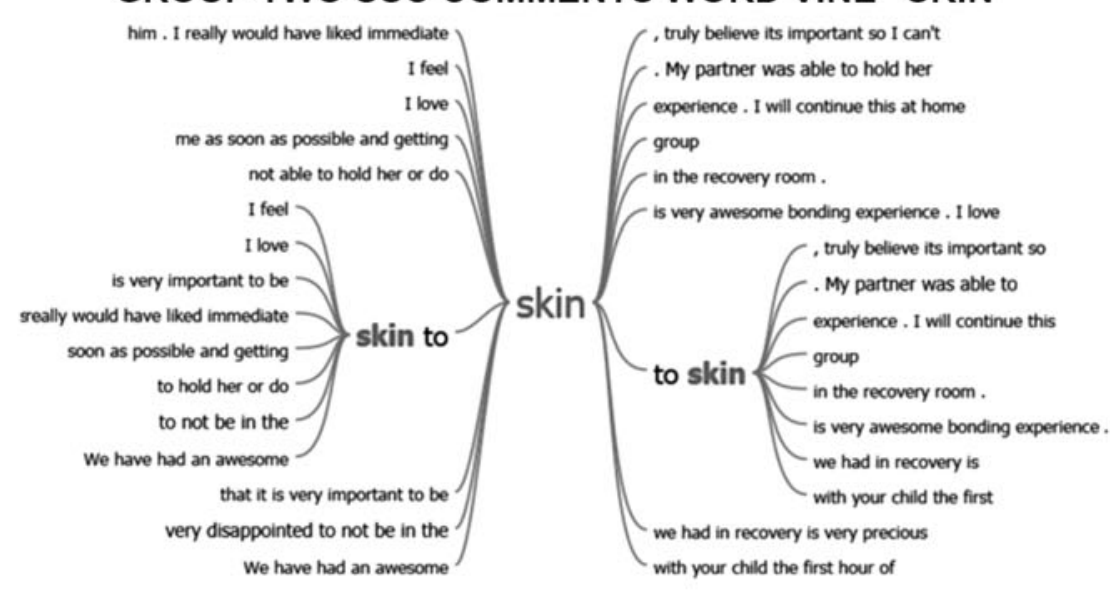

GROUP TWO SSC SENTIMENTS

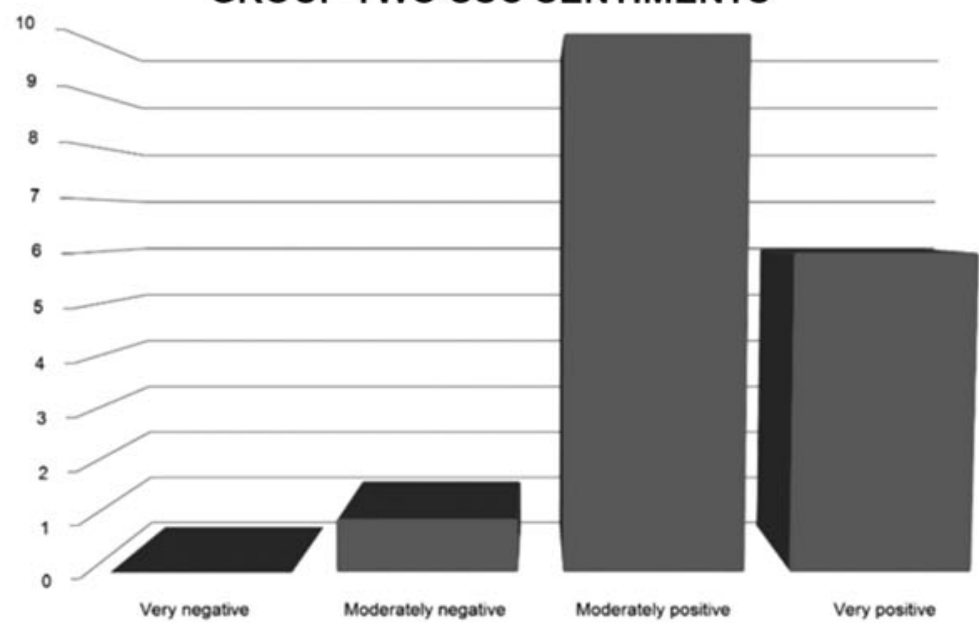

FIG. 1. (Continued). 
patient-centered approach. Bergman, ${ }^{36}$ a specialist in perinatal neuroscience, called for maternity policies that ensured zero separation of mothers and newborns, "at all costs." Health professionals have an ethical responsibility to implement immediate and interrupted SSC and minimize separation as the standard of care during and after medically uncomplicated cesarean birth.

\section{Acknowledgments}

The authors thank Kathryn Corso, MSN, RNC-OB, CEFM, CNE; Teresa Ellis, ADN, RNC-OB; Julie Gestes, ADN, RN; Susana Hernandez, BSN, RN; Taylor Houser, DNP, APRN, CNM, C-EFM; Judith Joiner, BSN, RNCMNN; Jennifer Killingsworth, BSN, RN; Whitney Patterson, BSN, C-EFM; Olha Prijic, BSN, RNC-MNN, NE-BC; Tracey Smith, BSN, RNC-OB, and Kristen Westmoreland, BSN, RN for participating in the study team; Mary Grace Leveille, $\mathrm{PhD}, \mathrm{APRN}, \mathrm{ACNP}-\mathrm{BC}$ for research guidance and mentoring; and the entire women and children's staff at Baylor University Medical Center for embracing research and adoption of best practices; Patricia S. Yoder-Wise, RN, EdD, NEA-BC, ANEF, FAONL, FAAN; Karin Cadwell, PhD RN FAAN IBCLC ANLC; Jeni Stevens, PhD, RM, RN, IBCLC; and Rowena Robles, for feedback on early drafts of this article; and the Texas Tech University Health Sciences Center Clinical Research Institute for assistance with this research; and the patients and families who participated in the study.

\section{Disclosure Statement}

No competing financial interest exists.

\section{Funding Information}

This research study was funded by a $\$ 20,000$ seed grant award from Texas Tech University Health Sciences Center School of Nursing Office of Research.

\section{References}

1. Colombo L, Crippa BL, Consonni D, et al. Breastfeeding determinants in healthy term newborns. Nutrients 2018;10: E48.

2. World Health Organization, UNICEF. Implementation and guidance: Protecting, promoting, and supporting breastfeeding in facilities providing maternity and newborn servicesthe revised Newborn-friendly Hospital Initiative. Available at https://who.int/nutrition/publications/infantfeeding/bfhiimplementation-2018.pdf (accessed August 29, 2019).

3. Holmes AV, McLeod AY, Bunk M. ABM protocol \#5: Peripartum breastfeeding management for the healthy mother and infant at term. Breastfeed Med 2013;8:469473.

4. American Academy of Pediatrics Section on Breastfeeding. Breastfeeding and the use of human milk. Pediatrics 2012; 129:e827-e841.

5. Cleveland L, Hill CM, Pulse WS, et al. Systematic review of skin-to-skin care for full term, healthy newborns. J Obstet Gynecol Neonatal Nurs 2017;46:857-869.

6. Stevens J, Schmied V, Burns E, et al. Immediate or early skin-to-skin contact after a cesarean section: A review of the literature. Matern Child Nutr 2014;10:456-473.
7. Moore ER, Bergman N, Anderson GC, et al. Early skin-toskin contact for mothers and their healthy newborns. Cochrane Database Syst Rev 2016;2016:1-158.

8. Crenshaw JT. Healthy birth practice \#6: Keep mother and newborn together-it's best for mother, newborn, and breastfeeding. J Perinat Educ 2019;28:108-115.

9. Cadwell K, Brimdyr K, Phillips R. Mapping, measuring, and analyzing the process of skin-to-skin contract and early breastfeeding in the first hour after birth. Breastfeed Med 2018;13:485-491.

10. Brimdyr K, Cadwell K, Stevens J, et al. An implementation algorithm to improve skin-to-skin practice in the first hour after birth. Matern Child Nutr 2017;14:e12571.

11. Centers for Disease Control and Prevention. Breastfeeding: About breastfeeding - why it matters. Updated 2019. Available at https://cdc.gov/breastfeeding/about-breastfeeding/whyit-matters.html (accessed August 29, 2019).

12. Boatin AA, Schlotheuber A, Betran AP, et al. Within country inequalities in caesarean section rates: Observational study of 72 low and middle income countries. BMJ 2018; 360:k55.

13. Betrán AP, Ye J, Moller AB, et al. The increasing trend in cesarean section rates: Global, regional and national estimates: 1990-2014. PLoS One 2016;11:e0148343.

14. Császár-Nagy N, Bókkon I. Mother-newborn separation at birth in hospitals: A possible risk for neurodevelopmental disorders? Neurosci Biobehav Rev 2018;84:337351.

15. Safari K, Saeed AA, Hasan SS, et al. The effect of mother and newborn early skin-to-skin contact on initiation of breastfeeding, newborn temperature and duration of third stage of labor. Int Breastfeed J 2018;13:108.

16. Smith ER, Hurt, L, Chodhury R, et al. Delayed breastfeeding initiation and infant survival: A systematic review and meta-analysis. PLoS One 2017;12:e0180722.

17. NEOVITA Study Group. Timing of initiation, patterns of breastfeeding, and infant survival: Prospective analysis of pooled data from three randomized trails. Lancet Glob Health 2016;4:e266-e275.

18. Takahashi Y, Tamakoshi K, Matsushima M, et al. Comparison of salivary cortisol, heart rate, and oxygen saturation between early skin-to-skin contact with different initiation and duration times in healthy, full-term infants. Early Hum Dev 2011;87:151-157.

19. Beiranvand S, Valizadeh F, Hosseinabadi R, et al. The effects of skin-to-skin contact on temperature and breastfeeding successfulness in full-term newborns after cesarean delivery. Int J Pediatr 2014;2014:e846486.

20. Bystrova K, Ivanova V, Edhborg E, et al. Early contact versus separation: Effects on mother-infant interaction 1 year later. Birth 2009;36:97-109.

21. Widström A, Lilja G, Aaltomaa-Michalias P, et al. Newborn behaviour to locate the breast when skin-to-skin: A possible method for enabling early self-regulation. Acta Paediatr 2011;100:1-7.

22. Karimi FZ, Heidarian Miri HH, Salehian M, et al. The effect of mother-infant skin-to-skin contact after birth on the third stage of labor: A systematic review and metaanalysis. Iran J Public Health 2019;48:612-620.

23. World Health Organization, UNICEF. Baby-Friendly Hospital Initiative: Revised, updated, and expanded for integrated care. Updated 2009. Available at http://whqlibdoc.who.int/ publications/2009/9789241594967_eng.pdf (accessed August 29, 2019). 
24. Morgan PJ, Halpern S, Lo J. The development of a maternal satisfaction scale for caesarean section. Int $J$ Obstet Anesth 1999;8:165-170.

25. Conroy CC, Cottrell BH. The influence of skin-to-skin contact after cesarean on breastfeeding rates, infant feeding responses, and maternal satisfaction. J Obstet Gynecol Neonatal Nurs 2015;44(Suppl 1):S61.

26. Billner-Garcia R, Spilker A, et al. Skin to skin contact: Newborn temperature stability in the operating room. $M C N$ Am J Matern Child Nurs 2018;43:158-162.

27. Vila-Candel R, Duke K, Soriano-Vidal FJ, et al. Affect of early skin-to-skin mother infant contact in the maintenance of exclusive breastfeeding? experience in a health department in Spain. J Hum Lact 2018;34:304-312.

28. Guala A, Goscardini, L, Visentin R, et al. Skin-to-skin contact in cesarean birth and duration of breastfeeding: A cohort study. Sci World J 2017;2017:1940756.

29. Hung KJ, Berg O. Early skin-to-skin after cesarean to improve breastfeeding. MCN Am J Matern Child Nurs 2011; 36:318-324.

30. Gouchon S, Gregori D, Picotto A, et al. Skin-to-skin contact after cesarean delivery: An experimental study. Nurs Res 2010;59:78-94.

31. Yuksel B, Ital I, Balaban O, et al. Immediate breastfeeding and skin-to-skin contact during cesarean section decreases maternal oxidative stress, a prospective randomized casecontrolled study. J Matern Fetal Neonatal Med 2015;29: 2691-2696.
32. Bramson L, Lee JW, Moore E, Montgomery S, et al. Effect of early skin-to-skin mother-infant contact during the first 3 hours following birth on exclusive breastfeeding during the maternity hospital stay. J Hum Lact 2010; 26:130-137.

33. Brady K, Bulpitt D, Chiarelli C. An interprofessional quality improvement project to implement maternal/infant skin-to-skin contact during cesarean delivery. $J$ Obstet Gynecol Neonatal Nurs 2014;43:488-496.

34. Sundin CS, Mazac LB. Implementing skin-to-skin care in the operating room after cesarean birth. MCN Am J Matern Child Nurs 2015;40:249-255.

35. Kelly PA, Classen KA, Crandall CG, et al. Effect of timing of the first bath on healthy newborn's temperature. J Obstet Gynecol Neonatal Nurs 2018;47:608-619.

36. Bergman NJ. The neuroscience of birth-and the case for zero separation. Curationis 2014;37:e1-e4.

Address correspondence to: Jeannette T. Crenshaw, DNP, MSN, LCCE, NEA-BC School of Nursing

Texas Tech University Health Sciences Center 3601 4th Street Stop 6294

Lubbock, TX 79430-6264

E-mail:jeannette.crenshaw@ttuhsc.edu 